\title{
Investigation of cesarean sections at Konya Training and Research Hospital Obstetrics and Gynecology Department between 2010 and 2015
}

\author{
Zeynep Ozturk Inal ${ }^{1}$, Hasan Ali Inal ${ }^{1}$, Hasan Kucukkendirci ${ }^{2}$, Ayla Sargin Oruc ${ }^{3}$ \\ ${ }^{1}$ Konya Education and Research Hospital, Konya, Turkey \\ ${ }^{2}$ Necmettin Erbakan University Meram Medical Faculty, Konya, Turkey \\ ${ }^{3}$ Guven Hospital, Ankara, Turkey
}

\begin{abstract}
Objective: Analysis of the annual distribution of cesarean sections and indications between 2010 and 2015 in our clinic. Material and methods: Medical records of 10,437 cesarean section patients from a total number of 24,283 deliveries performed at Department of Obstetrics and Gynecology between 2010-2015 were evaluated retrospectively. The indications for Cesarean section were analyzed and compared based on years.

Results: The lowest cesarean section rate was $18.67 \%$ in 2011 and the highest rate was $24.5 \%$ in 2013, and the annual rates were close to each other in this 6-year period $(p>0.05)$. History of uterine surgery was the indication with the highest rate of $49.52 \%$, while fetal distress was the second most frequent with $12.53 \%$; presentation anomalies were observed as the most frequent third indication with $7.55 \%$, and umbilical cord prolapse was the least frequent indication with $0.33 \%$.

Conclusions: Patient education about normal delivery and providing means for pain control during normal delivery, improvement in physical conditions of the clinics, frequent and regular training of the assisting staff with obstetrics physicians are important to diminish the rates of primary cesarean sections. In addition, a normal delivery after a previous cesarean section must be encouraged.
\end{abstract}

Key words: cesarean, vaginal delivery, cesarean section rates, indications

\section{INTRODUCTION}

Modern cesarean section is a surgical procedure involving incision of the abdominal wall and uterus followed by extraction of the baby, weighing above 500 grams, in cases where labor is obstructed; cesarean section first performed by the German gynecologist, Ferdinand Adolf Kehrer in 1881 [1,2]. The first successful cesarean delivery was performed in 1974 in West Virginia, U.S. and in 1915 in the U.K. Professor Eduardo Porro of Italy suggested hysterectomy in 1876 to avoid hemorrhage during cesarean section. The mortality risk in the mother was around $80 \%$ due to hemorrhage during cesarean section in the 1500s. In recent years, cesarean section operations are highly developed and the rates of risks such as maternal death, bleeding and infection have decreased prominently. However, it should be kept in mind that cesarean section, which is accepted as a routinely performed delivery method, is still an operation and it is healthier to be performed only in required indications [2].

In 1985, the World Health Organization (WHO) recommended that cesarean section rates should not pass $15 \%$, referring to the countries in which the perinatal mortality rates are low [3]. However, in recent years, cesarean section delivery rates are 25\% in Europe and Latin American countries, 31.8\% in the U.S., and has increased to a record-breaking level of $46 \%$ in China [4]. In Turkey, the rate of cesarean section deliveries among all deliveries was $21.0 \%$ in $2002,42.7 \%$ in $2009,45.5 \%$ in 2010, 46.6\% in 2011, 48.0\% in 2012 and 50.4\% in 2013 according to the Turkish Public Health Institution data [5]. 
Higher rates of detection of fetuses at risk with the assistance of high technology, increased pregnancy age and decreased maternity, preference of cesarean section due to a previous cesarean section delivery could be counted among the causes for the increase in cesarean section rates all over the world. Furthermore, the tendency of surgeons to perform cesarean section to protect themselves from lawsuits that are increased in recent years, maternal fear of normal delivery, and the possibility to plan the time and the place of delivery with cesarean section have also contributed to the increase [6].

In our study, the annual distributions of cesarean section and the indication rates between 2010-2015 in our clinic were evaluated and analyzed.

\section{MATERIAL AND METHODS}

Approval of the education planning and coordination committee of our hospital was obtained and a total number of 24.283 patients who had given live births or stillbirths at 20 weeks of gestation and/or above 500 grams of birth weight between January $1^{\text {st }} 2010$ and December $31^{\text {st }} 2015$ in our clinic were included in the study after retrospective investigation of the digital record system and delivery records from the hospital archives. Data of 10.437 cesarean section cases including maternal age, gestational age at delivery, birth weight, gender of the baby and cesarean section indication were evaluated annually and compared.

The statistical Package for Social Sciences (SPSS) (version 15.0, SPSS, Inc, Chicago, IL, USA) was used for the statistical analysis. The Kolmogorov-Smirnov analysis was performed in order to evaluate the normal distribution of the constant variables. The Student-t test and the One-Way Anova Tests were performed for the analysis of the data demonstrating a normal distribution. The Mann-Whitney $U$ test was performed in order to analyze the non-normally distributed data. The Chi-square and the Fisher exact tests were used for the categorical parameters. A $p$ value of $<0.05$ was accepted as statistically significant.

\section{RESULTS}

A total number of 24,283 deliveries had been performed at the Konya Training and Research Hospital, Department of Obstetrics and Gynecology in between January $1^{\text {st }} 2010$ and December $31^{\text {st }} 2015$, of which 10,437 were cesarean (42.98\%) and 13.846 (57.02\%) were vaginal deliveries; the primary cesarean section rate was $21.23 \%$, the recurrent cesarean section rate was $21.75 \%$, and the general rate of cesarean section deliveries was determined as $42.98 \%$. The annual distribution of vaginal and cesarean deliveries has been presented in Table 1 and the percentage changes have been displayed in Figure 1. Accordingly, the lowest rate of primary cesarean sections was observed in 2011 with $18.67 \%$, while the highest rate was observed in 2013 with $24.50 \%$ and the rates were close to each other including the whole 6-year period.

The mean maternal age for cesarean deliveries was observed to increase over the years; however, the mean gestational weeks, the mean newborn birth weight and the newborn gender distributions were not observed to exhibit any differences (Tab. 2).

Table 1. The distribution of vaginal and cesarean births according to the years

\begin{tabular}{|c|c|c|c|c|}
\hline $\begin{array}{c}\text { Year } \\
(n=24.283)\end{array}$ & $\begin{array}{c}\text { Vaginal birth } \\
(n=13.846) \\
(57.02 \%)\end{array}$ & $\begin{array}{c}\text { Cesarean } \\
(n=10.437) \\
(42.98 \%)\end{array}$ & $\begin{array}{l}\text { Primary cesarean } \\
\qquad(n=5.157) \\
(21.23 \%)\end{array}$ & $\begin{array}{c}\text { Recurrent cesarean } \\
(\mathbf{n}=\mathbf{5 . 2 8 0 )} \\
(21.75 \%)\end{array}$ \\
\hline $\begin{array}{c}2010 \\
3.234 \\
(\%)\end{array}$ & $\begin{array}{c}1.943 \\
(60.09)\end{array}$ & $\begin{array}{c}1.291 \\
(39.91)\end{array}$ & $\begin{array}{c}604 \\
(18.67)\end{array}$ & $\begin{array}{c}687 \\
(21.24)\end{array}$ \\
\hline $\begin{array}{c}2011 \\
4.187 \\
(\%)\end{array}$ & $\begin{array}{l}2.601 \\
(62.13)\end{array}$ & $\begin{array}{c}1.586 \\
(37.87)\end{array}$ & $\begin{array}{c}876 \\
(20.92)\end{array}$ & $\begin{array}{c}710 \\
(16.95)\end{array}$ \\
\hline $\begin{array}{c}2012 \\
4.749 \\
(\%)\end{array}$ & $\begin{array}{c}2.740 \\
(57.70)\end{array}$ & $\begin{array}{c}2.009 \\
(42.30)\end{array}$ & $\begin{array}{c}1.040 \\
(21.89)\end{array}$ & $\begin{array}{c}969 \\
(20.41)\end{array}$ \\
\hline $\begin{array}{l}2013 \\
4029 \\
(\%)\end{array}$ & $\begin{array}{c}2.103 \\
(52.20)\end{array}$ & $\begin{array}{c}1.926 \\
(47.80)\end{array}$ & $\begin{array}{c}987 \\
(24.50)\end{array}$ & $\begin{array}{c}939 \\
(23.30)\end{array}$ \\
\hline $\begin{array}{c}2014 \\
4.363 \\
(\%)\end{array}$ & $\begin{array}{c}2.403 \\
(55.08)\end{array}$ & $\begin{array}{c}1.960 \\
(44.92)\end{array}$ & $\begin{array}{c}877 \\
(20.10)\end{array}$ & $\begin{array}{c}1.083 \\
(24.82)\end{array}$ \\
\hline $\begin{array}{c}2015 \\
3.721 \\
(\%)\end{array}$ & $\begin{array}{c}2.056 \\
(55.26)\end{array}$ & $\begin{array}{c}1665 \\
(44.74)\end{array}$ & $\begin{array}{c}773 \\
(20.77)\end{array}$ & $\begin{array}{c}892 \\
(23.97)\end{array}$ \\
\hline
\end{tabular}




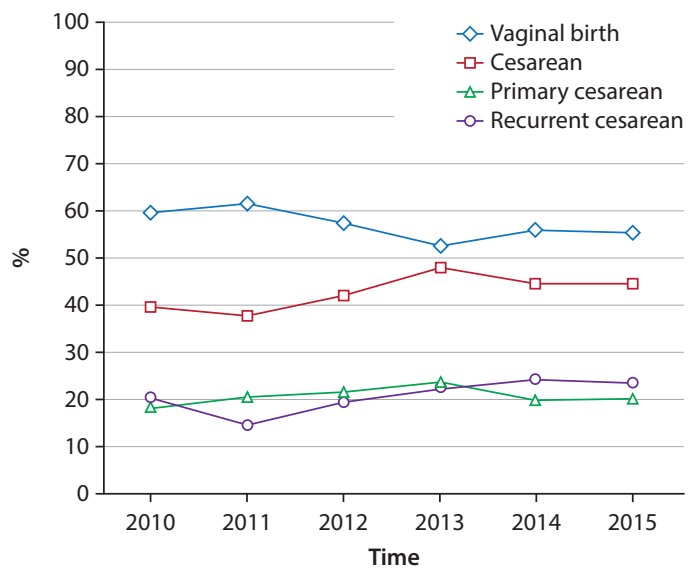

Figure 1. The distribution of vaginal and cesarean births according to the years

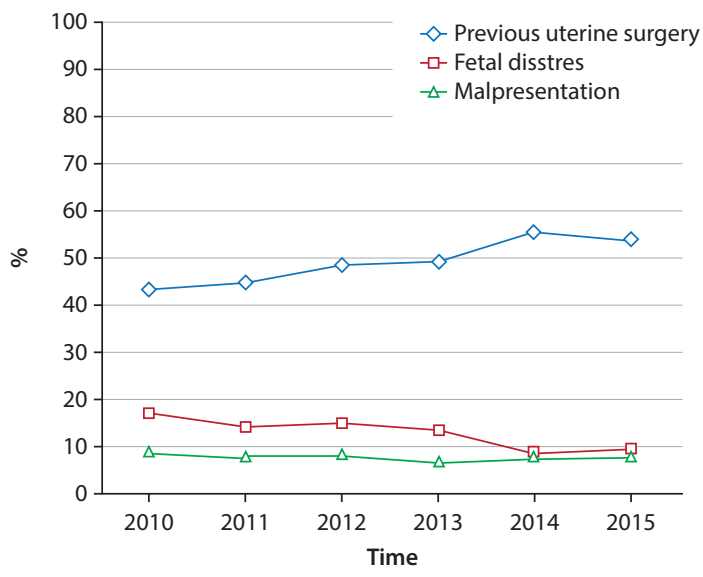

Figure 2. The distribution of previous uterine surgery, fetal distress and malpresentation according to the years

Table 2. The distribution of age, gestational age and birth weight undergoing cesarean section according to the years

\begin{tabular}{|c|c|c|c|c|c|}
\hline Years & $\begin{array}{c}\text { Age } \\
\text { (years) }\end{array}$ & Gastationel age & Birth weight [g] & \multicolumn{2}{|c|}{ Gender (\%) } \\
\hline 2010 & $27.45 \pm 4.76$ & $37.1 \pm 4.4$ & $2.920 \pm 480$ & 52.1 & 47.9 \\
\hline 2011 & $27.84 \pm 5.24$ & $37.3 \pm 4.2$ & $3.040 \pm 460$ & 53.2 & 46.8 \\
\hline 2012 & $28.42 \pm 5.68$ & $37.5 \pm 4.1$ & $3.100 \pm 490$ & 51.7 & 48.3 \\
\hline 2013 & $28.82 \pm 4.82$ & $37.2 \pm 4.3$ & $3.080 \pm 470$ & 52.6 & 47.4 \\
\hline 2014 & $29.42 \pm 5.36$ & $37.4 \pm 4.5$ & $3.120 \pm 430$ & 51.4 & 49.6 \\
\hline 2015 & $29.86 \pm 4.62$ & $37.5 \pm 4.4$ & $3.140 \pm 420$ & 51.5 & 48.5 \\
\hline
\end{tabular}

The main indications for cesarean section observed in our study have been presented in Table 3. Previous uterine surgery was seen in $49.52 \%$, fetal distress in $12.53 \%$, presentation anomalies in $7.55 \%$, cephalopelvic disproportion in $4.75 \%$, hypertensive disease of pregnancy (mild-moderate preeclampsia, eclampsia, HELLP) in 3.93\%, multiple pregnancy in $4.02 \%$, prolonged labor in $3.77 \%$, macrosomia in $3.64 \%$, placental anomalies (placenta previa, placenta detachment) in $2.35 \%$, maternal request in $0.84 \%$, umbilical cord prolapse in $0.33 \%$ and other anomalies in $6.77 \%$. The increase in cesarean section rates due to previous uterine surgery and macrosomia as indications compared to the first two years (2010 and 2011) was statistically significant $(p<0.05)$. The cesarean section rates due to prolonged labor were decreased in the last 4 years compared to the first two years, and the fetal distress was decreased in the last 2 years compared to the first 4 years significantly $(p<0.05)$. The annual distribution of the most frequent three cesarean indications have been demonstrated in Figure 2.

\section{DISCUSSION}

In our study, which included cesarean deliveries in our clinic between 2010-2015, we have observed the primary cesarean section rate to be $21.23 \%$, and the recurrent cesarean section rate as $21.75 \%$, and the general rate of cesarean section deliveries has been determined as $42.98 \%$; the most frequent three indications have been determined as previous uterine surgery (49.52\%), fetal distress (12.53\%) and presentation anomalies (7.55\%). We have also found that maternal age was increased over the years; however, the birth week, the newborn birth weight and the newborn gender distribution were not changed.

In the light of improvements achieved in anesthesia and antisepsis, cesarean section is among the most common operations performed in obstetrics and gynecology clinics. The cesarean section rates, which vary between states, were $24-45 \%$ between 1980-1988 in the United States, while it was $15.1 \%$ in Colorado and $26.6 \%$ in Mississippi in 1996. In England and Scotland, the cesarean section rate is $18 \%$, while it is $31.4 \%$ in Porto Rico and $35 \%$ in Brazil $[7,8]$. The cesarean section rates worldwide are estimated as $16 \%$ in 2012 , while this rate is estimated as $24 \%$ in the European region and $28 \%$ in high-income countries, and $32 \%$ in middle-income countries. In Turkey, according to the Ministry of Health data, the cesarean section rate was $14 \%$ in 1998 , $21.0 \%$ in $2002,21.4 \%$ in $2003,42.7 \%$ in $2009,45.5 \%$ in 2010 , $46.6 \%$ in $2011,48.0 \%$ in 2012 , and $50.4 \%$ in 2013. In 2009, according to data obtained from the Ministry of Health, 39.3\% 


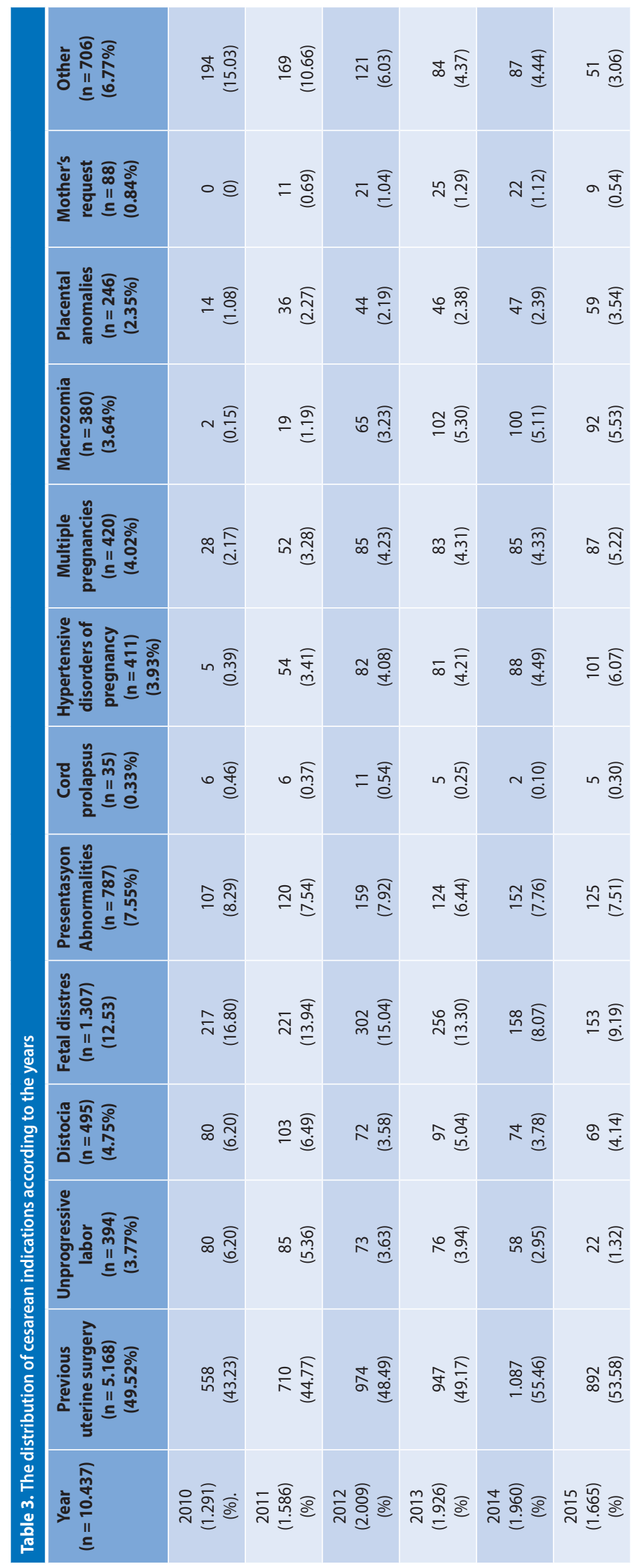

of the deliveries in public hospitals, $63.2 \%$ of deliveries in university hospitals and $47.8 \%$ of the deliveries in private hospitals were cesarean deliveries. In 2013, the rate of cesarean sections in private hospitals was increased (67.9\%) and the rate was not changed in public (36.0\%) and university (63.0\%) hospitals [5]. The Central Anatolian region of Turkey including the Konya province had a cesarean section rate of $16 \%$ in 2002 , which is below the general rate of Turkey, and 49\% in 2013, which is similar to the general rate of Turkey [5]. In our study, the total cesarean delivery rate was close to the mean of the region and Turkey with $47.8 \%$. During the total 6 years included in our study, the cesarean delivery rates were in an increasing trend in the last 4 years of the study compared to 2010 and 2011 in general.

Development of improved imaging techniques for detection of fetal well-being, postponement of pregnancy due to reasons such as career development, increased number of previous cesarean patients, prolonged labor, and assisted reproduction treatment and breech delivery could be counted as the most important causes for the increase in cesarean delivery rates [9]. In a Cochrane database review, fetal monitoring was reported to increase the cesarean delivery at a rate of $40 \%$; however, the frequencies of newborn intensive care and cerebral palsy were not increased [4]. Avoidance of intervened deliveries such as vacuum extraction and forceps usage and increased rates of malpractice lawsuits due to complications also contribute to the increase.

Lidegaard reported the most important cause of increased cesarean delivery rates as the wide window of indications and the liberal approach to the patient for cesarean delivery decision [9]. Miller suggested that encouragement of vaginal delivery after a previous cesarean delivery would decrease the rates and showed that cesarean delivery rates decreased to $34 \%$ in 1993 from 39\% in 1980 [10].

Previous uterine surgery has been established as the most important indication in all studies evaluating cesarean delivery indications [11-13]. We found the most common cesarean delivery indication as previous uterine surgery with a rate of $49.52 \%$ consistent with the literature. We think that the reason for these findings is the 'Once cesarean, always cesarean' 
principal, which is accepted in our country as well. It was reported that patients who had been operated with a lower segment transverse incision for cesarean delivery could try vaginal delivery if the patient's pelvis is clinically eligible, if the fetus is below 4000 grams, if there is no history of uterine surgery of rupture and if the patient could be monitored, and in case of emergencies, this could be switched to cesarean delivery [14].

Maternal weight gain before and during pregnancy and smoking have been shown to increase the primary cesarean section rates [15]. It is known that the prevalence of hypertensive diseases, gestational diabetes, preeclampsia and operative deliveries are increased for advanced age pregnancies [16].

Fetal distress has been determined as the second most common cesarean section indication with $12.53 \%$ rate in our study. Fetal distress rates increased over time as the electronic fetal monitoring became more available. In a study conducted by Coşkun et al. [17], the fetal distress-caused cesarean section rate was found as $13.8 \%$. In the same study, breech presentation as an indication was determined at a rate of $2.9 \%$, while in our study this was $5.4 \%$.

In our clinic, cesarean delivery is recommended in case of breech presentation; however, in cases of previous vaginal delivery and no additional indications (macrosomia, dystocia, presentation anomalies, etc.) for cesarean section, vaginal delivery could be recommended after provision of detailed information about the possible risks. It should be a concomitant decision of the patient and the doctor.

Hypertensive disease of pregnancy was determined in $3.93 \%$ of the cases in our study. In our clinic, if cervical maturity is eligible, induced vaginal delivery is attempted for this indication; if not, cesarean section is decided.

Cesarean delivery is performed in all cases of placental anomalies in our clinic and the cesarean section indication rate was $2.35 \%$. This rate in our clinic is higher compared to other studies as our clinic is a tertiary health care facility [12]. In case of placental detachment, if the fetus is alive and mature and vaginal delivery is not expected soon, cesarean section should be preferred. If the fetus is not alive and the patient is hemodynamically stable, and no other obstetric cause preventing vaginal delivery is observed, vaginal delivery could be preferred.

Multiple pregnancies were evaluated as a separate group in our study and the rate was $4.02 \%$. The most common presentation in multiple pregnancies is head-head presentation. In cases of the first twin presenting breech or transverse, cesarean section is recommended as the first choice [18]. Most clinicians prefer cesarean delivery as the first choice in pregnancies complicated by three or more fetuses.
It was shown that $59 \%$ of the obstetricians approved of cesarean section in case of maternal request in another study [10]. Elective cesarean is preferred by the patients as advanced age pregnancies, assisted reproduction pregnancies and tendency to avoid labor pain are increased. It is suggested that elective cesarean delivery could prevent intrapartum neurological damage and $\mathrm{CP}$; however, it was shown in some studies that the delivery technique has no effect on the acute and prolonged neurological prognosis [19, 20].

Pulmonary morbidity was found to be higher in elective cesarean section than vaginal delivery, and cesarean sections performed earlier than $39^{\text {th }}$ week were shown to further increase the risk. The same study emphasized the increase in autoimmune diseases (e.g. type 1 diabetes, Crohn's disease, multiple sclerosis) and allergic diseases (e.g. asthma, allergic rhinitis, atopic dermatitis) parallel to the increase in cesarean section deliveries [21].

The World Health Organization (WHO) recommends early discharge of the mother and newborn to protect them from hospital acquired infections [22]. It should be kept in mind that the rates of morbidities such as hemorrhage, sepsis, pulmonary embolism, endometritis and pneumonia are higher in cesarean section than normal delivery, and furthermore, it could cause late complications such as placental detachment, placenta previa, and placenta accreta [23].

Despite our clinic being a tertiary healthcare center where high risk deliveries are performed, the cesarean section rate is below the average rate observed in Turkey. However, $42.98 \%$ is almost three-fold the rate recommended by $\mathrm{WHO}$, and we think that awareness of the indications for cesarean section in the first pregnancy, education and encouragement of mothers about vaginal delivery, education and training of midwives and encouragement of vaginal delivery in cases with previous cesarean section are important to decrease this rate.

\section{Conflict of interest}

None declared.

\section{REFERENCES}

1. Todman D. A history of caesarean section: from ancient world to the modern era. Aust N Z J Obstet Gynaecol. 2007; 47(5): 357-361, doi: 10.1111/j.1479-828X.2007.00757.x, indexed in Pubmed: 17877591.

2. Bt Maznin NL, Creedy DK. A comprehensive systematic review of factors influencing women's birthing preferences. JBI Libr Syst Rev. 2012; 10(4): 232-306, doi: 10.11124/jbisrir-2012-46, indexed in Pubmed: 27819971.

3. World Health Organization. Appropriate technology for birth. Lancet. 1985; 2: 436-7.

4. National Health Service Information Centre [Internet]. London: NHS maternity statistics, England: 2008-09. http://www.ic.nhs.uk.

5. T.C. Saglik Bakanligi Halk Sagligi Kurumu, Saglik Istatistikleri Yillig 2013. http://sbu.saglik.gov.tr/Ekutuphane/Yayin/485.

6. Yalınkaya A, Bayhan G, Kale A, et al. Dicle Universitesinde 20 yillik sezaryen oranları ve endikasyonlari. T Klin Jinekol Obst. 2003; 13: 356-359. 
7. Juez G, Lucero $E$, Ventura-Juncá P. [Intrauterine growth according to fetal sex and maternal parity]. Rev Chil Pediatr. 1989; 60(4): 204-207, indexed in Pubmed: 2485509.

8. Curtin SC, Martin JA. Births: preliminary data for 1999. Natl Vital Stat Rep. 2000; 48(14): 1-20, indexed in Pubmed: 10957864.

9. Lidegaard $O$, Jensen LM, Weber T. Technology use, cesarean section rates, and perinatal mortality at Danish maternity wards. Acta Obstet Gynecol Scand. 1994; 73(3): 240-245, indexed in Pubmed: 8122506.

10. Miller WJ, Nair C, Wadbere J. Declining cesarean sections rates: a continuing trend Helth Statistics Devision at Statistics Canada, Ottawa. Helth Rep. 1996; 8: 17-24.

11. Demir BC, Ocakoglu G, Ozerkan K, et al. Cesarean delivery rates and changing indications in our clinic between 2000-2010. Uludag Universitesi Tıp Fakultesi Dergisi. 2012; 38(2): 123-127.

12. UzuncakmakC, Guldas A, Aydin S, et al. Investigation of cesarean sections at Istanbul Training and Research Hospital Obstetrics and Gynecology Department between 2005 and 2012. Istanbul Medical Journal. 2013; 14(2): 112-116, doi: 10.5152/imj.2013.19.

13. Mutryn CS. Psychosocial impact of cesarean section on the family: a literature review. Soc Sci Med. 1993; 37(10): 1271-1281, indexed in Pubmed: 8272905.

14. Martel MJ, MacKinnon CJ, Martel MJ, et al. Clinical Practice Obstetrics Committee, Society of Obstetricians and Gynaecologists of Canada, Clinical Practice Obstetrics Committee of the Society of Obstetricians and Gynaecologiests of Canada. Guidelines for vaginal birth after previous Caesarean birth. J Obstet Gynaecol Can. 2004; 26(7): 660-83; quiz 684, indexed in Pubmed: 15248936.
15. Bianco A, Stone J, Lynch L, et al. Pregnancy outcome at age 40 and older Obstet Gynecol. 1996; 87(6): 917-922, indexed in Pubmed: 8649698.

16. Smith GCS, Cordeaux Y, White IR, et al. The effect of delaying childbirth on primary cesarean section rates. PLoS Med. 2008; 5(7): e144, doi: 10.1371/journal.pmed.0050144, indexed in Pubmed: 18597550.

17. Coskun A, Kostu B, Ercan O, et al. Kahramanmaras II Merkezinde 2004 ve 2006 yıllarındaki doğumların karşılaştırılması. TJOD Dergisi. 2007; 4: $168-72$.

18. ACOG educational bulletin. Special problems of multiple gestation. Number 253, November 1998 (Replaces Number 131, August 1989). American College of Obstetricians and Gynecologists. Int J Gynaecol Obstet. 1999; 64(3): 323-333, indexed in Pubmed: 10366060.

19. Flamm BL. Once a cesarean, always a controversy. Obstet Gynecol. 1997; 90(2): 312-315, doi: 10.1016/S0029-7844(97)00263-9, indexed in Pubmed: 9241315.

20. Gregory KD, Korst LM, Cane $P$, et al. Vaginal birth after cesarean and uterine rupture rates in California. Obstet Gynecol. 1999; 94(6): 985-989, indexed in Pubmed: 10576187.

21. Neu J, Rushing J. Cesarean versus vaginal delivery: long-term infant outcomes and the hygiene hypothesis. Clin Perinatol. 2011; 38(2): 321-331, doi: 10.1016/j.clp.2011.03.008, indexed in Pubmed: 21645799.

22. World Health Organization, Pospartum Care Of The Mother and New born: A Pratical Guide. http://whqlibdoc.who.int/hq/1998/WHO_RHT_ MSM_98.3.pdf.

23. Vangen S, Stoltenberg C, Skrondal A, et al. Cesarean section among immigrants in Norway. Acta Obstet Gynecol Scand. 2000; 79(7): 553-558, indexed in Pubmed: 10929954. 